\title{
LOS CONTRATOS DE CONSUMO EN EL DERECHO COLOMBIANO Y EL DERECHO COMPARADO*
}

\author{
JUAN CARLOS VILLALBA CUELLAR** \\ UNIVERSIDAD MILITAR NUEVA GRANADA
}

Recibido/ Received/ Recebido: 09-05-2011 - Aceptado/ Accepted / Aprovado: 09-11-2011

\begin{abstract}
Resumen
Las relaciones económicas entre productores y consumidores encuentran en el derecho un tratamiento especial, que debe ser tenido en cuenta también por los estudiosos de las ciencias económicas. En el derecho privado moderno los contratos de consumo aparecen como una categoría contractual que merece especial atención, dada la preocupación de proteger al contratante débil en aras de buscar la justicia contractual. En el derecho comparado tanto doctrinaria como legalmente, la teoría de los contratos de consumo se han desarrollado. Sin embargo, en el ámbito jurídico colombiano no se ha consolidado realmente este marco doctrinario y legal. Este artículo pretende hacer un aporte frente a este vacío, consolidando algunos conceptos básicos de la teoría de los contratos de consumo apoyándose en el derecho comparado y en algunos avances doctrinales y legales a nivel nacional.
\end{abstract}

Palabras clave: Contratos, Consumo, Relación de consumo, Protección al consumidor.

\section{CONSUMPTION CONTRACTS IN COLOMBIAN AND COMPARED LAW}

\begin{abstract}
Economic relations among producers and consumers find in law a special treatment that should be considered by economic science academics. In modern private law, consumption contracts appear as a contractual category that deserves special attention due to the importance of protecting the weak contractor in order to seek for contractual justice. Consumption contract theory has been developed in both doctrinaire and legally compared law. However, in Colombian juridical scope the doctrinaire and legal framework has not been sufficiently developed. This article seeks to do a contribution filling this gap, consolidating some basic concepts of consumption contract theory based on compared law and some doctrinaire and legal advances at national level.
\end{abstract}

Keywords: Contracts, Consumption, Consumption relation, Consumer protection.

\footnotetext{
* Este artículo pertenece a la investigación denominada "El sistema de protección al consumidor en Colombia. Una perspectiva desde el derecho comparado", correspondiente al grupo de "Derecho Privado", línea de investigación sobre "Derecho Económico y de los Negocios" que se adelanta en el Centro de Investigaciones Jurídicas, Políticas y Sociales (C.I.D.E.R.) de la Facultad de Derecho de la Universidad Militar Nueva Granada.

** Abogado, docente e investigador. Adscrito a la línea en Derecho Económico y de los Negocios del grupo en Derecho Privado del Centro de Investigaciones de la Facultad de Derecho de la Universidad Militar Nueva Granada. Magíster LLM en Derecho Francés, Europeo e Internacional de Negocios de la Universidad Panthéon-Assas Paris II y el Instituto de Derecho Comparado de Paris (Francia). Especialista en docencia universitaria. Correo electrónico: juan.villalba@unimilitar.edu.co
} 


\title{
OS CONTRATOS DE CONSUMO NO DIREITO COLOMBIANO E NO DIREITO COMPARADO
}

\begin{abstract}
Resumo
As relações econômicas entre produtores e consumidores encontram no direito um tratamento especial que deve ser considerado também pelos estudiosos das ciências econômicas. No direito privado moderno os contratos de consumo aparecem como uma categoria contratual que merece especial atenção dada a preocupação de proteger ao frágil contratante em função de procurar a justiça contratual. No direito comparado a teoria dos contratos de consumo se desenvolveu tanto doutrinária como legalmente. No entanto, no âmbito jurídico colombiano não se consolidou realmente este marco doutrinário e legal. Este artigo pretende dar sua contribuição frente a este vazio, consolidando alguns conceitos básicos da teoria dos contratos de consumo, apoiando-se no direito comparado $e$ em alguns avanços doutrinais e legais a nível nacional.
\end{abstract}

Palavras chave: Contratos, Consumo, Relação de consumo, Proteção ao consumidor.

Villalba J. (2011) Los contratos de consumo en el derecho colombiano y el derecho comparado. En: Revista de la Facultad de Ciencias Económicas de la Universidad Militar Nueva Granada. rev. fac.cienc.econ, XIX (2).

\section{Introducción}

La doctrina clásica contenida en los códigos de derecho privado aún vigente concibe al contrato como un acuerdo de voluntades, fruto de una negociación previa entre las partes, con miras a la creación, modificación, o extinción de relaciones jurídicas patrimoniales (obligaciones). Vega (2001) se refiere a este aspecto: "El capitalismo decimonónico no tardaría en transformar de raíz el substrato de todas las relaciones interpersonales convirtiéndolas en relaciones de cambio basadas en transacciones; en cambiar el telón de fondo y erigir un nuevo oráculo: el mercado. El paroxismo por el comercio, apoyado por el auge de la producción industrial, trastocaría los moldes habituales para el tráfico de bienes y servicios. Los productores invadirían con sus bienes facturados en serie toda esfera otrora reservada a los artesanos. Asoma la sociedad de masas en la que prima lo impersonal, el anonimato, la despersonalización".

Se parte de la premisa, un negocio se celebra entre partes iguales, capaces de determinar el contenido del negocio en paridad de condiciones, de igual a igual. Pérez (2009) nos dice al respecto que: "bajo el imperio de la regla pacta suntservanda, la libertad de contratación y el efecto obligatorio de los contratos tuvieron su cumplida aplicación. Se consideraba que las partes contratantes se hallaban a un mismo nivel y en una misma situación de libertad y poder. Puesto que todos los hombres, según lo enseña la escuela individualista, nacen libres e iguales, y pueden a su arbitrio obligarse o permanecer sin compromisos, cuando se deciden a contratar lo hacen en desarrollo del poder autónomo de su voluntad y una vez que han discutido de igual a igual las cláusulas del convenio con su contraparte". No obstante, en caso de que alguno de los intervinientes pudiera verse afectado al otorgar su manifestación de voluntad en el momento de la celebración del contrato, por elementos externos o vicios del consentimiento (error, fuerza o violencia y dolo), estos mismos códigos contemplaron algunos remedios legales que permitirían atacar la eficacia del contrato.

Al tenor de las mismas doctrinas, cuando las manifestaciones de voluntad de las partes se encuentran, se forma el consentimiento, como fruto de un mutuo acuerdo, resultado de una previa discusión de las condiciones contractuales que determinan la clase de operación económica que se quiere. Las partes han escogido el negocio y lo han dotado de contenido de acuerdo a lo que consideran conveniente para ellos. Se trata, en efecto, de un verdadero acuerdo de voluntades. 
Sin embargo, esas premisas hoy en día se encuentran en entredicho, las relaciones económicas en la sociedad moderna se han complejizado, lo cual ha planteado retos al derecho privado. En efecto, la venta de bienes y la prestación de servicios en masa marcaron a partir de la revolución industrial el cambio de una economía artesanal a una economía de corte industrial (Ghersi, 2005). La aparición de medios de comunicación como la televisión, la radio, la internet, a lo que se suma el surgimiento de las denominadas nuevas tecnologías de la información y la comunicación NTIC, facilitaron el acceso de los productores de bienes y prestadores de servicios a los hogares de los consumidores de forma masiva. Además las técnicas de comercialización y marketing tuvieron un desarrollo importante en los últimos años.

En el contexto de todos estos cambios, el contrato como fenómeno económico y jurídico ha sufrido también transformaciones. La búsqueda de la justicia contractual sobrepasa el estrecho límite de la voluntad de las partes como ley contractual, asegura Cárdenas (2007) al respecto que:

"existe el constante propósito de asegurar que el contrato corresponda a un ideal de justicia, el cual por lo demás corresponde al propósito constitucional de un orden justo... Se trata por consiguiente, de asegurar que las partes puedan adoptar la decisión que más les convenga, que lo hagan libremente, que en aquello sobre lo cual existe deliberación se preserve la justicia y que durante la ejecución del contrato se conserve el reequilibrio querido por los contratantes, incluyendo los riesgos que cada uno haya asumido"

El contrato típico de la sociedad moderna no es el que describen los códigos decimonónicos, la mayoría de los contratos que celebran los hombres hoy en día tienen unas características que difieren de los postulados clásicos del derecho privado, son los contratos de la sociedad de consumo. Al respecto señala Rusconi (2009):

"La denominada revolución industrial trajo consigo la mutación del fenómeno de in- tercambio de bienes en la sociedad. Al introducirse la fabricación y la elaboración a gran escala de los bienes destinados a los consumidores, con la consiguiente comercialización masiva, la estructura "bipersonal" de las instituciones jurídicas clásicas, y fundamentalmente del derecho de los contratos, se vieron desbordadas. Ellas habían nacido y evolucionado en torno a la ideología liberal, en la cual la regla más sagrada era la autonomía de la voluntad individual y el abstencionismo estatal".

Las técnicas de marketing y la publicidad le dan al productor un poder significativo frente al consumidor, capaz de determinar sus necesidades y manipular su voluntad en la toma de decisiones en el mercado. Igualmente, las empresas estudian los comportamientos del consumidor para poder influir en las decisiones de estos a través de los que se denomina la psicología del consumidor. Las decisiones que toman los consumidores no son siempre racionales, el neuromarketing, la publicidad subliminal, las técnicas de ventas agresivas, entre otras prácticas, afectan el comportamiento del consumidor. Todo esto hace que el estudio de las manifestaciones de voluntad de los consumidores y sus efectos jurídicos se cada vez más compleja.

Hoy en día la máxima preocupación del legislador en materia de derecho privado a nivel global radica en la búsqueda de la justicia contractual, sobre todo en el aspecto más sensible de las relaciones jurídicas privadas, la protección al contratante débil. En los diferentes ordenamientos jurídicos como respuesta a estos cambios se crearon fórmulas de regulación de los contratos en los que esa debilidad era manifiesta. Es así como a partir de la década de los 70 se comenzó a consolidar en algunos países desarrollados, una política de protección al consumidor que se tradujo en la regulación de actividades económicas y la reglamentación de algunos contratos sensibles a algunas prácticas comerciales que iban en detrimento de los consumidores. Este fenómeno se dio específicamente en los Estados Unidos con el surgimiento de los denominados movimientos de consumidores y posteriormente en Europa dentro del marco de la integración económica, a través de directivas que 
desarrollaron la materia en el ámbito comunitario hasta contar hoy en día con un nivel alto de protección al consumidor y una normatividad unificada.

La mayoría de los ordenamientos jurídicos hoy en día cuentan con una normativa de protección al consumidor que regula situaciones precontractuales y contractuales en las cuales se ven involucrados los consumidores. La noción de contrato de consumo apareció hace algunos años y es aceptada plenamente como una categoría contractual especial, merecedora de estudio aparte. Señala Diez Picazo \& Gullón (2001) que a partir del momento en que se consiguen los estatutos de los consumidores, hay dos regulaciones sobre derechos de los contratos: un derecho de contratos general o un derecho de contratos común- que se rige por los esquemas tradicionales de los contratos- y el derecho de los destinatarios finales. Sin embargo, esta categoría contractual en el derecho colombiano no ha sido incorporada plenamente a los estudios doctrinales. Ese vacío doctrinal pretende ser remediado, a manera introductoria, a través del presente artículo y de antemano justifica la necesidad de abordar el tema en el contexto colombiano.

En ese orden de ideas, este artículo pretende estudiar los contratos de consumo para justificar la existencia de esta categoría contractual, partiendo de la conceptualización que se ha hecho de estos en el derecho comparado y el nacional. Se buscará determinar sus principales características, los principios que los gobiernan, su tipología, así como las vicisitudes que pueden surgir alrededor de su celebración.

Para tal fin, se hará una aproximación a la teoría de los contratos de consumo, tomando como base los elementos principales de la teoría contractual, a saber, el concepto de contrato, sus categorías principales, sus características delimitantes y sus principales problemáticas como la ineficacia y validez. No se pretende de ninguna manera agotar el tema, tan solo lograr unas ideas generales y de carácter introductorio sobre el asunto.

Como quiera que este estudio hace parte de una investigación que toma como base el derecho compa- rado, además de la legislación colombiana, se tomaran como referente algunas legislaciones que tienen regulados estos contratos.

\section{Concepto de contrato de consumo}

Se puede intentar hacer una aproximación conceptual afirmando que un contrato de consumo es un acuerdo de voluntades entre un productor y un(os) consumidor(es) para la adquisición de bienes o la prestación de servicios. En el contrato de consumo existe una relación jurídica de consumo de carácter convencional. Los contratos de consumo constituyen así una nueva categoría contractual, tomando el esquema de clasificación de los contratos, más no un nuevo tipo de contrato, tomando en cuenta la operación económica que encierran, tal como la compraventa, el arrendamiento, etc.

Rinessi (2006) señala que "contrato de consumo es el celebrado entre un consumidor final - persona física o jurídica- con una persona física o jurídica, pública o privada, que actuando profesional u ocasionalmente, en calidad de productora, importadora o distribuidora, comercialice bienes o preste servicios, y que tenga por objeto la adquisición, uso o goce de estos por parte del primero, para su uso privado, personal o familiar". Igualmente, el código peruano de protección al consumidor define en el artículo 45 el contrato de consumo de la siguiente manera: "El contrato de consumo tiene como objeto una relación jurídica patrimonial en la cual intervienen un consumidor y un proveedor para la adquisición de productos o servicios a cambio de una contraprestación económica", debe destacarse que la reciente normatividad peruana en la materia es la única (en las que fueron materia de estudio) en que aparece definido el contrato de consumo. Stiglitz (1999) lo define como "el celebrado a título oneroso entre un consumidor final- persona física o jurídica-, con una persona física o jurídica que actúe profesional $\mathrm{u}$ ocasionalmente o con una empresa productora de bienes o prestadora de servicios, pública o privada y que tenga por objeto la adquisición, uso o goce de los mismos, por parte del primero, para su uso privado familiar o social". 
Para Lorenzetti (s.f) se trata de una modalidad de celebración de contratos en la que se tiene en cuenta la finalidad de las partes, por lo cual la definición de contrato de consumo en la doctrina argentina está estrechamente relacionada con la noción de relación de consumo. En los extremos del vínculo obligacional que nace en los contratos de consumo necesariamente se encontraran un productor y un consumidor.

\section{Contrato de consumo y relación de consumo}

La noción de relación de consumo aparece en la doctrina argentina en la Constitución Política de 1994, la cual en su artículo 42 establece que "Los consumidores y usuarios de bienes y servicios tiene derecho, en la relación de consumo, a la protección de su salud, seguridad e intereses económicos; a una información adecuada y veraz, a la libertad de elección y a condiciones de trato equitativo y digno...". A partir de la consagración constitucional se desarrolló toda una teoría alrededor de la relación de consumo como vínculo jurídico especial, en ese momento la norma de protección al consumidor (ley 24.240) de anterior promulgación, no contemplaba la noción de relación de consumo. La reforma a la ley 24.240, que se dio con la ley 26.361 de 2008, incluiría en la misma la noción de relación de consumo en su artículo 3, al siguiente tenor: "Relación de consumo es el vínculo jurídico entre el proveedor y el consumidor o usuario". En el ámbito comunitario la resolución 123/96 del Mercosur, define la relación de consumo como "el vínculo que se establece entre el proveedor que, a título oneroso, provee un producto o presta un servicio y quien lo adquiere o utiliza como destinatario final. Equipárense a esta la provisión de productos y la prestación de servicios a título gratuito cuando se realicen en función de una eventual relación de consumo". En Brasil, el capítulo II del Código de defesa do Consumidor, establece de manera amplia la política nacional de relaciones de consumo, sin definir la misma norma que se entiende por relación de consumo. En el Perú el reciente- mente expedido código de protección y defensa del consumidor del 2 de septiembre de 2010, define la relación de consumo así: "Es la relación por la cual un consumidor adquiere un producto o contrata un servicio con un proveedor a cambio de una contraprestación económica". Debe advertirse desde ahora que la noción de relación de consumo es ajena al derecho europeo.

Entendida así, la relación de consumo es un vínculo obligacional entre un productor y un consumidor. Para Diego Zetner citado por Ghersi (2005) "se trata de un vínculo jurídico de fuente legal que liga al proveedor de bienes y servicios con el consumidor que los adquiere o utiliza como destinatario final, así como en todos aquellos que se ven afectados por sus consecuencias o, en general, por la actividad de los proveedores". En el derecho colombiano no existe una norma que haga alusión a la relación de consumo, legalmente esta noción no existe. Sin embargo, la Superintendencia de Industria y Comercio, entidad encargada de proteger al consumidor, en sus conceptos hace alusión a la relación de consumo. Por ejemplo, en concepto del año 2000, la Superintendencia, para determinar el ámbito de aplicación de la norma de protección al consumidor tuvo en cuenta la existencia de una relación de consumo'. En otro concepto posteriormente agregó: "Si bien en nuestro ordenamiento jurídico y específicamente en el Decreto 3466 de 1982 no se define la relación de consumo, teniendo en cuenta las definiciones contenidas en el artículo 1 del mencionado decreto, se puede determinar que la relación de consumo es la que se presenta entre el productor, proveedor o expendedor y el consumidor"2. La ley 1480 de 2011 define al consumidor o usuario "como toda persona natural o jurídica que, como destinatario final, adquiera, disfrute o utilice un determinado producto, cualquiera que sea su naturaleza para la satisfacción de una necesidad propia, privada, familiar o doméstica y empresarial cuando no esté ligada intrínsecamente a su actividad económica. Se entenderá incluido en el concepto de consumidor el de usuario". Sin embargo, esta ley no define la relación de consumo, aunque hace expresa mención de la misma en

\footnotetext{
Concepto 01085864 del 22 de Noviembre de 2001. Superintendencia de Industria y Comercio.

Concepto 03025237 del 09 de Mayo de 2003. Superintendencia de Industria y Comercio.
} 
el artículo 2: "Las normas contenidas en esta ley son aplicables en general a las relaciones de consumo (...)".

La Corte Constitucional igualmente se refirió a la relación de consumo, diciendo "En este sentido, el Decreto 3466 de 1982 consagra las normas relativas a la idoneidad, la calidad, las garantías, las marcas, las leyendas, las propagandas y la fijación pública de precios de bienes y servicios y la responsabilidad de sus productores, expendedores y proveedores aplicables a toda relación de consumo, entendida ésta como aquella que se establece entre productores, distribuidores, expendedores y consumidores, en donde estos últimos se encuentran en una relación de asimetría en relación con los primeros y en búsqueda de la satisfacción de sus necesidades. Así las cosas, la protección del consumidor establecida en el citado decreto se predica de las relaciones de consumo en tanto que la vulneración de los derechos allí señalados se produce dentro de la cadena de comercialización de bienes y servicios. Alli los consumidores se encuentran en una relación de desventaja frente a los comercializadores, lo que implica un necesario restablecimiento de la igualdad entre las partes que, sólo se logra a través de normas protectoras de la parte más débil de la relación"3.

En este orden de ideas, encontramos que con el fin de delimitar el ámbito de aplicación de las relaciones de consumo para los ordenamientos jurídicos resulta importante definir el contenido y alcance de las expresiones "consumidor" y "productor" o "proveedor".

De manera general, se define al consumidor como la persona natural o jurídica que como destinatario final adquiere un bien o un servicio para la satisfacción de una necesidad personal, familiar o doméstica ${ }^{4}$. Esta noción presenta algunas variables en los diferentes ordenamientos jurídicos, en el ámbito comunitario europeo no se acepta como consumidor a las personas jurídicas, en algunas legislaciones como la mexicana, la peruana o la costarricense se ha cobijado al pequeño empresario como consumidor a pesar de actuar dentro del ámbito de su actividad profesional. Se distingue además que el consumidor que amerita protección es el consumidor "medio" perspicaz e informado. La Superintendencia de Industria y Comercio (s.f, 35) define "el consumidor racional [como] la persona que interpreta la publicidad en la forma natural en la que le es transmitida, sin darles un alcance distinto a las palabras e imágenes del que naturalmente tienen, $e$ interpretándolas en una forma superficial, como lo haría una persona que no tiene un conocimiento especializado del producto o servicio anunciado. Así las cosas, el consumidor racional no es el experto, pero tampoco es el ignorante absoluto, sino que es una persona o un consumidor común y corriente".

En el derecho comunitario europeo además se han identificado grupos especiales de consumidores, por ejemplo los niños o los ancianos, dignos de un grado más alto de protección contractual. Inclusive en el ámbito doctrinal se viene predicando desde hace un tiempo que resulta más apropiado definir el campo de aplicación del derecho del consumo en consideración del acto o relación jurídica de consumo que con respecto a una categoría única de individuos. Señala Rinessi (2006) citando a Benjamín que "El contenido del derecho del consumidor es la relación jurídica de consumo (hecho o acto jurídico) practicado por un profesional y un no profesional o consumidor. Como no existe una categoría homogénea, particular, universal, bien individualizada de consumidores, se dice que el derecho del consumidor se aplica más apropiadamente a las relaciones jurídicas de consumo que a una categoría especial y única de individuos". En este mismo sentido, se puede entender a Poillot (2006).

En el contexto del Mercosur la definición comunitaria de consumidor y las definiciones legales de los estados miembros hacen expresa mención a la relación de consumo (Piris, 2004). Esta última posición refuerza la importancia de la relación de consumo como elemento delimitador del ámbito de aplicación del derecho del consumo.

Concepto 02108233 del 17 de Enero de 2003 (Superintendencia de Industria y Comercio) citado por Corte Constitucional en Sentencia C-1141 de 2000.

4 En Villalba (2009) se hace un estudio amplio del concepto de consumidor. 
En cuanto a la noción de productor, proveedor o profesional, los ordenamientos jurídicos a su vez definen al otro sujeto de la relación de consumo. El decreto 3466 de 1982 (estatuto del consumidor colombiano) define al productor como: "Toda persona natural o jurídica, que elabore, procese, transforme o utilice uno o más bienes, con el propósito de obtener uno o más productos o servicios, destinados al consumo público. Los importadores se reputan productores respecto de los bienes que introduzcan al mercado nacional".

La mayoría de los ordenamientos jurídicos hace la diferencia ente productor y proveedor, buscando diferenciar entre quienes elaboran o producen bienes o servicios y quienes los distribuyen, mientras que legislaciones como la argentina tiene un concepto único de proveedor comprensivo de las otras categorías $^{5}$. En todo caso ambos tienen vocación para verse involucrados en las relaciones de consumo. En el contexto comunitario europeo se habla de profesional, entendido este como "la persona que con un objetivo económico, ejerce una actividad de manera habitual y organizada" (Auguet, 2008), "la persona natural o jurídica que actúa dentro del marció de una actividad habitual y organizada de producción, distribución o prestación de servicios" (Calais-Auloy, 2006). El Código del consumo francés y la LGDCU española no definen específicamente al profesional. La noción de productor o profesional en todo caso es más pacifica que la de consumidor, en algunos casos se ha debatido si las personas jurídicas de derecho público pueden ser considerados productores o profesionales, a lo cual se responde mayoritariamente en sentido afirmativo y se hace palpable en la prestación de servicios públicos. La ley 1480 de 2011 reitera en nuestro ordenamiento jurídico la distinción entre productor y proveedor 6 .
En ese orden de ideas, se debe entender como productor, proveedor o profesional a toda persona que haga parte de la cadena de comercialización, producción, montaje, creación, construcción, transformación, distribución, importación comercialización. El tratamiento que el legislador le dé a la responsabilidad de estos en las relaciones de consumo es muy importante, en la mayoría de casos la responsabilidad entre los miembros de la cadena productiva y de comercialización por los daños ocasionados por un producto defectuoso puesto en el mercado es de carácter solidario.

Debe hacerse hincapié que el productor o profesional es una persona que se considera en posición de dominio frente al consumidor, debido a su poder económico, por lo tanto en los casos en que algunas personas que estrictamente son productores o profesionales han invocado ser cobijados por una norma de protección al consumidor, el juez o las autoridades competentes nacionales han sido renuentes a aceptar la cobertura de la norma de protección al consumidor (Villalba, 2009). No obstante algunos ordenamientos jurídicos han acentuado el margen de protección al considerar al pequeño empresario como sujeto del derecho del consumo, tal y como lo afirmamos en líneas anteriores. Este es definitivamente el punto crucial, que genera inconvenientes o disparidad de criterios legales a la hora de definir el ámbito de aplicación de las normas de protección al consumidor, saber si una persona (natural o jurídica) que actúa en el marco de su actividad profesional debe ser protegida o no.

Lo anterior nos permite afirmar que la noción de relación de consumo es amplia, no se circunscribe al campo contractual, el vínculo jurídico en la re-

La ley 24.240 de 1996 actualizada por la ley 26.361 de 2008 define al proveedor como: "La persona física o jurídica de naturaleza pública o privada, que desarrolla de manera profesional, aun ocasionalmente, actividades de producción, montaje, creación, construcción, transformación, importación, concesión de marca, distribución y comercialización de bienes y servicios, destinados a consumidores o usuarios".

6 La Ley 1480 define productor a "Quien de manera habitual, directa o indirectamente, diseñe, produzca, fabrique, ensamble o importe productos. También se reputa productor, quien diseñe, produzca, fabrique, ensamble, o importe productos sujetos a reglamento técnico o medida sanitaria o fitosanitaria. Proveedor o expendedor: Quien de manera habitual, directa o indirectamente, ofrezca, suministre, distribuya o comercialice productos con o sin ánimo de lucro". 
lación de consumo puede derivar de una relación contractual o extracontractual, incluyendo el ámbito precontractual (Rinessi, 2006). La doctrina en el derecho comparado ha llevado este aspecto lejos, se concibe que habrá relación de consumo por ejemplo en un caso de publicidad engañosa, la propaganda se inscribe dentro de la época precontractual y una infracción a las normas sobre la materia en cuanto a la veracidad del mensaje, por ejemplo, ameritara la aplicación de normas de protección al consumidor. Entre el consumidor que recibe en el mensaje engañoso y el productor que lo emite hay una relación de consumo. Lo mismo sucederá en el caso de responsabilidad por productos defectuosos, habrá relación de consumo entre la persona que ha sufrido el daño y el productor, así entre ellos no exista un vínculo contractual, se trata de una relación de consumo de naturaleza extracontractual. La doctrina argentina ha insistido en adoptar una concepción amplia de la relación de consumo (Lorenzzetti, 2003; Rinessi, 2006), no obstante, señala al respecto Piris (2004) en su análisis de la normativa del Mercosur, que la tendencia legislativa se encamina a tomar un concepto restringido que comprende solamente relaciones contractuales onerosas y eventualmente gratuitas. La definición legal incluida en el código de defensa y protección del consumidor peruano ratifica esta tendencia.

Se puede colegir entonces que un contrato será de consumo cuando el vínculo jurídico derive de una relación de consumo convencional. En consecuencia para determinar si un contrato es de consumo se deberá hacer el análisis de la calidad de las partes y de las finalidades de estas en la celebración del negocio (criterio subjetivo), es decir, si el acuerdo de voluntades se da entre un productor (proveedor $\mathrm{o}$ profesional) y un consumidor, tomando como punto de partida para este análisis la definición legal que de cada uno de ellos se haya establecido. Así cualquier clase de contrato podrá ser de consumo (compraventa, arrendamiento, depósito, mutuo, etc.), se trata de una categoría contractual definida por la finalidad económica de las partes (criterio subjetivo) y no porque la finalidad económica del negocio sea idéntica en todos los casos (criterio objetivo). De este modo, puede haber compraventas, arrendamientos, mutuos, y en general cualquier clase de contratos de consumo, dependiendo de la finalidad de las partes, es decir, de la existencia de una relación de consumo. En concordancia con lo anterior, como quiera que el elemento delimitador de la aplicación del derecho del consumo a una relación contractual estriba en la existencia de una relación de consumo, pareciera más acertado hablar de relación de consumo que de contratos de consumo, prescindiendo de la necesidad de hablar de contrato de consumo, lo cual desvirtuaría la existencia de los contratos de consumo como categoría contractual autónoma.

Empero, la revisión de la doctrina en el derecho comparado permite identificar un aspecto adicio$\mathrm{nal}^{7}$, a pesar de lo señalado anteriormente, se insiste en hablar de contratos de consumo, tanto en el ámbito latinoamericano (donde se habla de relación de consumo) como en el europeo (donde no existe la noción de relación de consumo). En efecto, existen cierta clase de contratos que siempre serán de consumo, teniendo en cuenta la naturaleza de los mismos y no estarán sometidos necesariamente al análisis de la existencia de una relación de consumo, los denominaremos contratos objetivos de consumo. La doctrina cita los contratos financieros, de prestación de servicios públicos, contratos de tiempo compartido, de medicina prepagada, de telecomunicaciones, de ventas a distancia, créditos de consumo, entre otros. Las normas de protección al consumidor reglamentan generalmente este tipo de contratos. Por ejemplo, en Colombia en materia financiera y de prestación de servicios públicos los contratos celebrados con los usuarios tiene un ámbito especial de protección. La ley 142 de 1994 le da un tratamiento especial al contrato de servicios públicos, las partes del contrato son la empresa de servicios públicos y el suscriptor y/o usuario, se impone el deber de información y la inclusión de ciertas cláusulas puede ser sancionada por abuso de posición dominante. En materia financiera, la ley 1328 de 2009, deno-

\footnotetext{
La doctrina comparada sobre contratos de consumo asume diferentes clases de contratos de consumo, como los contratos bancarios, los contratos de tiempo compartido o time sharing, el contrato de medicina prepagada, los contratos de servicios públicos, entre otros.
} 
minada "reforma financiera", regula en su título I el régimen de protección al consumidor financiero, en el cual desarrolla aspectos contractuales como el deber de información y las cláusulas o prácticas abusivas con los consumidores. Las partes intervinientes de los contratos financieros son el cliente o usuario y la entidad financiera. Ninguna de las dos normas en mención hacen referencia a la existencia de una relación de consumo, no distinguen quién debe ser considerado consumidor como si lo hace el estatuto de protección al consumidor y este no se aplica por tratarse de normas especiales. Allí todas las relaciones son de consumo, ya que la noción usuario es genérica, no importa la finalidad del contrato para el usuario, por lo que estos contratos son contratos de consumo por naturaleza. Por ejemplo, será consumidora de servicios públicos domiciliarios una gran empresa que para el desarrollo de su finalidad económica consuma electricidad y agua potable.

Se trata de contratos de prestación de servicios (la mayoría de las veces) regulados generalmente de manera específica en los diferentes ordenamientos jurídicos, en algunos casos por razones de interés general (servicios públicos) o porque la praxis contractual demostró que se exhibían riesgos para el consumidor, normalmente por la posición de dominio que tiene una de las partes en el contrato. En este punto, la teoría general muestra su debilidad, porque se predica entonces la aplicación de las normas de protección al consumidor de manera general a personas que en sentido jurídico estricto no lo son. Por ejemplo, si una empresa (persona jurídica comerciante) abre una cuenta corriente en un banco, los dos sujetos del vínculo jurídico contractual son productores o profesionales, actúan en el marco de su actividad profesional, sin embargo la naturaleza del contrato implica la aplicación de normas de protección al consumidor. Lo mismo sucede en materia de cláusulas abusivas en la mayoría de los ordenamientos jurídicos, para efectos de cierto tipo de contratos regulados consumidores somos todos. Se ve entonces como se objetiva el análisis de los contratos de consumo en aras a maximizar el grado de protección al contratante, se puede afirmar que se trata en este caso de relaciones objetivas de consumo. Estas son las vicisitudes del derecho del consumo.

\section{Características de los contratos de consumo}

Los contratos de consumo presentan unas características comunes en los diferentes ordenamientos jurídicos que merecen ser referidas.

\subsection{Es un contrato asimétrico, entre desiguales}

El contrato de consumo es un contrato asimétrico, en el que las partes no tienen igualdad, una de las partes, el productor, es experto en la técnica de producción, posee toda la información relevante para la celebración del contrato, tiene un poder económico mayor y un poder de negociación que le permite imponer las condiciones contractuales. Esta asimetría se presenta de manera general en las relaciones de consumo y su principal causa es la información, el consumidor no siempre detenta la información relevante para la toma de decisiones en el mercado, quien posee la información y además es experto en el tema, el productor, determina qué información transmite al consumidor, de modo que ante una información insuficiente el consumidor tomará decisiones ineficientes. Márquez (2007) afirma que:

"en materia económica la protección al consumidor se requiere por la asimetría de la información que puede haber antes de la realización del negocio, y en el daño al mercado proveniente de los costos de transacción tan altos a los que deberían someterse los consumidores, entre ellos la obtención de la información principalmente. En un mercado de competencia perfecta, la información de los agentes es completa, es decir, todos los agentes tienen acceso a toda la información del mercado. Esta información completa se transmite a través del precio de los bienes y de los servicios. Si el mercado no es de competencia perfecta, y especialmente cuando tal causa está dada por la asimetría de la información debido a la información incompleta, se genera una posición de dominio de las que es fácil abusar por parte del conocedor de la información. El Estado debe corregir esta falla del mercado buscando eliminar las fortalezas adquiridas por los tenedores de la información cuando tal situación perjudique al mercado". 
Este análisis nació en la ciencia económica, fueron renombrados economistas los que mostraron los efectos de la asimetría informativa en el mercado, el hecho de que una de las partes en un contrato tenga mayor información que la otra genera un mal funcionamiento del mercado. El ejemplo descrito por Akerlof referente al mercado de los limones (autos usados) analiza un mercado de un producto en el cual los vendedores están mejor informados que los compradores acerca de la calidad del mismo, ante la deficiencia en la información los compradores harán ofertas suponiendo que los automóviles usados se venden por tener defectos "limones". Esto hace que los vendedores de los autos usados de alta calidad salgan del mercado, mientras que dos mercados diferentes en circunstancias competitivas, el de los autos de baja y los de alta calidad, se unifican en uno solo en el cual el precio de los autos cae y se nivela en el de los autos de mala calidad (Löfgren, Persson \& Weibull, 2002). El efecto consiste en que productos de diferente calidad se venderán a un mismo precio.

El fenómeno de la selección adversa se presenta cuando en un contrato la parte menos informada, al no poder distinguir entre la buena o mala calidad, acaba suponiendo que lo más probable es que le ofrezcan bienes de inferior calidad, por lo que generalmente acabará ofreciendo precios de peores calidades (Stiglitz \& Rothschild, 1976). El consumidor se verá perjudicado porque accederá a productos de inferior calidad y en muchos casos se sentirá engañado. En estas circunstancias se hace evidente la necesidad corregir esa asimetría a través de medidas de los propios agentes del mercado que le den confianza al consumidor, como por ejemplo dar garantías de calidad adicionales, o a través de medidas tomadas por el Estado para corregir esas asimetrías, como el deber de información contenido en las normas de protección al consumidor y la sanción de la omisión de información.

\subsection{Es un contrato de adhesión}

El contrato de adhesión se ha definido como "aquel en el cual el contenido contractual ha sido determinado con prelación, por uno solo de los contratantes al que se deberá adherir el co-contratante que desea formalizar una relación jurídica obligatoria" (Vallespinos, 1984). La ley 1480 de 2011, nuevo estatuto de protección al consumidor colombiano, regula por primera vez los contratos de adhesión aceptando implícitamente que los contratos de consumo son por excelencia contratos de este tipo y los define en el artículo 5 como: "Contrato de adhesión: Aquel en el que las cláusulas son dispuestas por el productor o proveedor, de manera que el consumidor no puede modificarlas, ni puede hacer otra cosa que aceptarlas o rechazarlas".

La contratación por adhesión es consecuencia de los cambios sociales, económicos y políticos experimentados en los últimos dos siglos, en una forma de contratación propia de la sociedad contemporánea, de la sociedad de consumo, en la cual se masifico la venta de bienes y la prestación de servicios. Al respecto Arrubla (2008) manifiesta:

"la contratación en masa requiere otro "ritmo que solo permite la elaboración de contratos en serie, severamente rígidos e inmodificables en su formulación" [citando a Stiglitz]. Se limita a la intervención de las partes, pues el examen del contenido del contrato queda reemplazado por la mecánica, consistente en formularios pre-impresos redactados por la empresa, con disposiciones manifiestamente favorables a sus intereses en detrimento de la parte débil del negocio (...) En este proceso hacia el contrato, es manifiesto que si el rol de la voluntad del consumidor queda reducido a nada, no participa en lo que será el esquema o contenido del contrato. La etapa de formación del negocio queda reducida a un esquema pre-impreso que el contratista detentador de la "fuerza económica" ha preparado con debido cuidado, y viene utilizando con anterioridad y piensa utilizarlo en el futuro. Sera la práctica y algunos fallos judiciales desfavorables a su intereses, los que le inviten en un futuro a incluir algunas modificaciones que seguramente realizara su departamento jurídi$\mathrm{co}$, pero en la cuales no intervendrá ninguno de los consumidores. Esta forma de contratar se impone al consumidor para que tome o deje el contrato sin que pueda discutir sus motivos. En muchas ocasiones tendrá que aceptarlo aun contra su voluntad, porque la empresa es monopolista o porque la competencia tiene exactamente las mismas formas contractuales". 
El contrato de adhesión evidentemente es un contrato desigual, Pérez Vives citado por Tamayo (1994) menciona que: "Hoy en día nadie discute que las partes no se hallan en un mismo pie de igualdad al contratar; que existen partes económica o jurídicamente fuertes, y partes económica y jurídicamente débiles; partes que están en condiciones de imponer sus cláusulas, y partes que fatalmente deben aceptarlas; partes que se presentan al campo convencional en calidad de vencedores, y partes que llegan allí en calidad de vencidos. Por eso se han ideado los contratos de adhesión y se ha admitido la extensión de la violencia, como causa de la nulidad de las convenciones, a aquellos casos que indican un indebido aprovechamiento de las circunstancias".

De esta manera, el contrato de adhesión desplazo al contrato "de libre discusión", hasta el punto que la gran mayoría de los contratos celebrados hoy en día de manera cotidiana por los consumidores son contratos predispuestos, (por ejemplo, el contrato de transporte, la compra y venta de bienes en el comercio formal, la prestación de servicios de toda naturaleza, los servicios públicos, la telefonía móvil, los servicios financieros, la televisión por suscripción, entre otras). La relativamente reciente aparición de este fenómeno explica por qué los códigos civiles antiguos no se detuvieron especialmente en su tratamiento legal. ${ }^{8}$

Vega (2001) por su parte insiste en la necesidad de no confundir entre el adherente y el consumidor, basado en la teoría que los mecanismos contractuales creados por el derecho común para proteger al contratante débil como la interpretación contra proferentem, la sanción de cierto tipo de cláusulas, entre otras; pese a proteger finalmente al consumidor no fueron creadas pensando en el ciudadano consumidor, es decir que no son suficientes porque no integran todos los principios y fundamentos propios de un estadio más evolucionado, el que corresponde al proceso evolutivo del consumerismo. Lo anterior parece acertado y permite afirmar que no se puede pretender responder a las necesidades de los consumidores con normas contractuales que no tuvieron como finalidad proteger al consumidor, el adherente de que habla el Código Civil no es el consumidor, su aplicación necesariamente se tornara insuficiente, se necesitan complejos normativos relativos a los contratos de consumo.

Algunos autores han identificado el contrato de adhesión con el contrato de consumo o han insertado la categoría de los contratos de consumo como una subcategoría de los contratos de adhesión, señala Ghersi (2005) al respecto: "El sistema contractual, como categoría universal (conjunción socioeconómica, cultural y jurídica), se desprende en dos estructuras: la del contrato de negociación individual, donde se cuenta con similar poder negocial, y la del de adhesión, en la que se advierte la presencia de un contratante minusválido, con asimetría genética y dinámica de las partes". El nuevo estatuto de protección al consumidor colombiano pareciera darles la razón al regular los contratos de adhesión celebrados con los consumidores.

Independientemente de esta discusión, es claro que los contratos de consumo en la gran mayoría de casos son contratos de adhesión, ya sea que se trate de contratos en los que el productor predispone el contenido del contrato a través de formatos previamente redactados que son presentados al consumidor, tal y como sucede en la prestación de servicios masivos; o que se trate de la venta de bienes o prestación de servicios en establecimientos, los cuales se celebran muchas veces de manera verbal, cuando la mercadería es puesta en estanterías o vitrinas con indicación de precios, frente a los cuales el consumidor solamente tiene la oportunidad de aceptar o no, ya que la posibilidad de discutir el contenido del acuerdo es nulo.

8 El contrato de adhesión desde su aparición generó debates en la doctrina acerca de su verdadera naturaleza jurídica, al respecto surgieron varias posiciones, la tesis contractualista que defendía la existencia de un acuerdo de voluntades en estos contratos, la tesis anti-contractualista, cuyo principal exponente fue Duguit, quien negaba la existencia de un verdadero acuerdo de voluntades, así como tesis intermedias que predicaban la validez del contrato, distinguiendo entre las cláusulas esenciales y las cláusulas accesorias . Hoy en día esta discusión parece superada y no se le niega la categoría de verdadero contrato al contrato de adhesión (Vallespinos, 1984). 
El contrato de adhesión es un contrato de aplicación común en las relaciones comerciales con consumidores, de ello no hay duda, es propicia para ser aplicada en relaciones contractuales en las que el poder económico de las partes es desigual, de allí su importancia al hablar de relaciones contractuales de consumo. Velilla (2001) al respecto afirma lo siguiente:

"Aunque el equilibrio contractual ha sido una preocupación constante del derecho de los contratos, la profunda transformación en las condiciones de la producción y de la distribución ha generalizado la celebración de contratos en los cuales el consumidor tiene que aceptar o rechazar en bloque las condiciones del contrato, sin tener la posibilidad de discutirlas con quien ha preestablecido el contrato (contratos de adhesión), quien puede incluso llegar a abusar de su poder, fabricando el contrato a su medida o incluyendo sólo las cláusulas que le sean más favorables (...) Una gran cantidad de autores sostiene que el derecho del consumidor es ante todo el derecho de los contratos de adhesión celebrados por los consumidores".

Frente a los riesgos que entrañan los contratos de adhesión, la reacción en la mayoría de los ordenamientos jurídicos por parte del legislador ha sido reglamentar el contrato de adhesión, especialmente los que se celebran con los consumidores, estos contratos tienen un tratamiento legal de carácter especial en procura de evitar que la parte fuerte de la relación contractual incurra en conductas que se consideran abusivas con el consumidor. Igualmente, frente a su interpretación este contrato tiene unas reglas especiales de protección. Mientras que en derecho comparado es prolífica esa normatividad de control de contratos de consumo, en Colombia no existía esa regulación, el Decreto 3466 de 1982, todavía vigente hasta abril de 2012 estatuto del consumidor, no se refiere a los contratos de adhesión, ni tampoco establece un régimen de control de cláusulas abusivas, el único instrumento que brinda es poder atacar un contrato por omisión al deber general de información.
Sin embargo, la Ley 1328 de 2009 en materia financiera definió los contratos de adhesión ${ }^{9}$, lo que también hace la Ley 1480 de 2011. Allí definió el contrato de adhesión ${ }^{10}$ en el artículo 5, en el artículo 37 y en adelante se ocupa de regular el contenido de estos contratos imponiendo el deber de información, la necesidad de uso del idioma castellano, caracteres legibles y la prohibición de espacios en blanco. En este sentido, prohíbe las cláusulas que permitan al productor $\mathrm{y} / \mathrm{o}$ proveedor modificar unilateralmente el contrato o sustraerse de sus obligaciones. En igual forma regula la cláusula de permanencia mínima, la cual ha sido fuente de problemas, sobre todo en materia de telecomunicaciones, y al respecto estipula que solamente podrá ser pactada de forma expresa cuando otorgue al consumidor una ventaja sustancial frente a las condiciones ordinarias del contrato y bajo esas circunstancias solamente se podrán pactar por una sola vez en el contrato sin que sean superiores a un año (artículo 41). Empero establece que el productor deberá ofrecer siempre al consumidor una opción de contratación alternativa a aquella que implique la inclusión de la cláusula de permanencia mínima para que este pueda escoger y decidir libremente. Durante la prórroga el consumidor podrá dar por terminado el contrato sin necesidad de pagar sumas que sanciones esta conducta. Finalmente se deja la puerta abierta a que se "pacte" una nueva cláusula de permanencia mínima, una vez vencida la primera, cuando se ofrezcan al consumidor nuevas ventajas en la celebración del contrato. Esta nueva regulación constituye un avance en la materia en Colombia, ya que se trata de un aspecto en que los consumidores se sentían maniatados y en el cual la autoridad de protección al consumidor carecía de un marco legal que le permitiese actuar con mayor efectividad. La práctica nos demostrará sus verdaderas bondades.

\subsection{Es un contrato reglado}

El contrato de consumo es un contrato reglado, con un nivel de protección especial derivado de la asime-

9 Son los contratos elaborados unilateralmente por la entidad vigilada y cuyas cláusulas y/o condiciones no pueden ser discutidas libre y previamente por los clientes, limitándose éstos a expresar su aceptación o a rechazarlos en su integridad.

10 El contrato de adhesión se define como aquel en el que las cláusulas son dispuestas por el productor o proveedor, de manera que el consumidor no puede modificarlas, ni puede hacer otra cosa que aceptarlas o rechazarlas. 
tría que se presenta entre las partes que intervienen en su celebración. Este marco se evidencia en todas las etapas del iter contractual, desde la formación del consentimiento, en la época precontractual, hasta en la ejecución y terminación del mismo. Las normas de protección al consumidor buscan controlar los riesgos inherentes a los contratos de consumo, elevando el grado de protección a favor de la parte débil de la relación contractual. Esta situación acentúa el intervencionismo del Estado en las relaciones jurídicas patrimoniales privadas relativas al consumo $y$ restringe en consecuencia la libertad contractual. La autonomía de la voluntad privada encuentra allí una barrera. Esto se evidencia en disposiciones tales como la reforma financiera de 2009 que prohibía en su artículo 11 la inclusión de cláusulas abusivas en los contratos financieros, así como la ocurrencia de prácticas abusivas en este tipo de contratos.

\subsection{El consentimiento informado}

La formación del consentimiento es una etapa fundamental en los contratos de consumo, puesto que la asimetría económica de las partes le da un poder de negociación especial al productor frente al consumidor, es decir, la formación del consentimiento como encuentro de las manifestaciones de voluntad no se da de una manera normal, como en los contratos de libre discusión, la decisión del consumidor se encuentra supeditada a la información que se le ha suministrado para tomar una decisión económica, información que detenta únicamente el productor y cuya comunicación puede controlar para manipular la decisión del consumidor. A este respecto señala Gómez Calle (2004) citado por Monsalve (2010):

"es reconocido por la comunidad jurídica internacional, que la igualdad entre los contratantes no es más que pura ficción. En materia de información es obvio que uno de los negociantes conoce o tiene la posibilidad de conocer más fácilmente que el otro aquellos datos, que afectando el contrato que se pretende celebrar en el futuro, le quedan más próximos, o si se quiere, dentro de su ámbito de conocimiento y/o influencia. Por tanto los deberes de información tienen, en fin, una finalidad protectora, que les sirve al propio tiempo de justificación, pretenden proteger al que se halla en una posición más débil, por su escasa información o su inexperiencia negocial".

Así se destaca el papel de la información como elemento determinador de la manifestación de voluntad del consumidor. Un consumidor debidamente informado tomara una decisión razonada, mientras quien no obtiene la debida información se obligara contractualmente sin tener plena consciencia de las condiciones, características y consecuencias jurídicas del contrato que celebra. Por lo tanto, el legislador se ha preocupado por reglamentar este aspecto a través de la obligación de informar el consentimiento del consumidor.

Este deber de información en la preparación del contrato de consumo se hace palpable a través de menciones obligatorias que tiene que hacer el productor al consumidor de diferentes maneras. Una primera forma es a través del cumplimiento del deber de información en el etiquetado de productos, en Colombia por ejemplo el Decreto 3466 de 1982 en el artículo 17 prescribía la obligatoriedad de indicar en las etiquetas o envases (o en anexos) las indicaciones y contraindicaciones del producto, así como su nocividad. En materia de medicamentos el decreto 677 de 1995 obliga en sus artículo 72 y 83 respectivamente, a que el empaque, rotulo o etiqueta de un medicamento o producto cosmético contenga unas menciones mínimas e impone en el artículo 79 obligaciones y restricciones para la información y publicidad de los medicamentos. Este decreto señala además que la información sobre medicamentos deberá ceñirse a la verdad y no podrá exagerarse sobre las bondades que pueda ofrecer su uso.

Una segunda forma en que se manifiesta la protección al consentimiento es a través del control de fijación de precios, la Ley 1480 de 2011 en el artículo 18 consagra la obligación de fijar los precios máximos al público por el sistema de fijación en lista o en los bienes mismos.

Debe tenerse en cuenta que la información solicitada se refiere a aspectos que en algunos casos son determinantes para la celebración del negocio jurídico, el precio es un elemento de la esencia del contrato y 
una indebida información acerca del mismo a la luz de la teoría general del negocio jurídico generaría la ineficacia del mismo. En lo atinente a las características o propiedades del bien, cualquier omisión, información insuficiente o engaño puede ser determinante para el consumidor, como por ejemplo si hubiese sabido que tenía contraindicaciones no lo hubiere adquirido.

En este último caso, un análisis desde la teoría general del negocio jurídico nos llevaría a predicar una ineficacia por error en la causa, o la configuración del dolo como vicio del consentimiento. No obstante se debe aclarar que este análisis se hace para resaltar la importancia de la información en las relaciones contractuales de consumo, ya que a pesar de que en estricto sentido jurídico si se podría hablar de ineficacia en este tipo de contratos, nos encontramos con un inconveniente de otra naturaleza, las cuantías de los asuntos de consumo y los mecanismos procesales convencionales que en Colombia existen para lograr la ineficacia de un negocio jurídico no permiten lograr la protección del consumidor desde el punto de vista contractual. (un consumidor no va a iniciar un procedimiento ordinario ante un juez civil para que se decrete la ineficacia de un contrato que versa sobre un televisor). Sin embargo queda planteado el interrogante ces necesario crear mecanismos procesales especiales para resolver asuntos contractuales que se adecuen a la naturaleza de los contratos de consumo? o por el contrario cestamos destinados a que los problemas derivados de esta clase de contratos se queden sin protección jurídica por falta de mecanismos procesales eficientes?

El deber de información se relaciona con lo que algún sector de la doctrina ha denominado los "deberes secundarios de conducta". Solarte $(2008,136)$ señala que "Dentro de este contexto, el carácter orgánico de la relación también se manifiesta en que al lado de las relaciones obligacionales en sentido estricto, existen otros deberes jurídicos, que se denominan "deberes secundarios de conducta", "deberes colaterales", o "deberes complementarios" o "deberes contiguos", tales como los deberes de información, protección, consejo, fidelidad o secreto, entre los más relevantes, que aunque no se pacten expresamente por las partes, se incorporan a los contratos en virtud del principio de la buena fe". Añadiendo Solarte que el deber de información es un deber secundario de conducta que se manifiesta así:

"es claro que si de las dos partes involucradas en un determinado contrato, una es conocedora de una ciencia u oficio, o de los pormenores de un mercado, y la otra carece de conocimientos en los campos citados, surgirá por virtud de la buena fe un deber en cabeza del sujeto informado de suministrar a su contraparte información objetiva, clara, oportuna y veraz, con el fin de que esta disponga de elementos de juicio suficientes para poder adoptar decisiones. El deber de información tiene, por regla general, una manifestación positiva, entendida como ha quedado enunciada, pero también presenta una expresión negativa, consistente en el deber jurídico de abstenerse de engañar o de inducir en error al otro contratante. Se considera que quien tiene la información debe tomar la iniciativa para efectos de suministrarla a la otra parte de la relación e, incluso, debe indagar sus necesidades y su estado de conocimiento sobre el tema materia del respectivo contrato"

Al respecto debe anotarse que resulta clara la existencia del deber de información, pero que dada la importancia del mismo, por lo menos en relaciones contractuales o precontractuales de consumo no se trata de un deber secundario, es un deber principal de las partes, especialmente del productor, quien detenta generalmente la información. La relevancia que le han dado al deber de información las normas de protección al consumidor no permite pasar a un segundo plano el cumplimiento del mismo.

\subsection{El contrato de consumo tiene unas reglas de interpretación especiales}

El contrato de consumo se caracteriza por la aplicación de un principio especial de interpretación, el principio favor consumitoris o pro consumidor, en virtud de este en caso de duda acerca de la interpretación de una norma o una cláusula en un contrato esta será interpretada en el sentido favorable al consumidor. El Código peruano de protección al consumidor lo define así: "en caso de duda insalvable en el sentido de las normas o cuando exista duda en los alcances de los contratos por adhesión y los 
celebrados en base a cláusulas generales de contratación, debe interpretarse en sentido más favorable al consumidor".

En el ordenamiento jurídico colombiano hay una norma en este sentido en el derecho común, el Código Civil contempla en el artículo 1624 el principio de interpretación contra proferentem, que indica que las cláusulas ambiguas que hayan sido dictadas por una de las partes, se interpretaran en contra de ella. Empero la norma en mención no es suficiente para lograr un margen correcto de protección al consumidor, tal y como lo señala Arrubla (2008), la norma es inocua e insuficiente porque en muchos casos la cláusula no es ambigua, por el contrario es muy clara, el problema radica en que sea abusiva para la parte que adhiere al contrato. El vacío normativo existente en nuestro país se evidenciaba entonces en la ausencia de mecanismos contractuales para controlar abusos contractuales con los consumidores. La Ley 1480 de 2011 de protección al consumidor en su artículo 34 contempla la referida regla de interpretación favorable en los siguientes términos: "Las condiciones generales de los contratos serán interpretadas de la manera más favorable al consumidor. En caso de duda, prevalecerán las cláusulas más favorables al consumidor sobre aquellas que no lo sean".

\section{La ineficacia de los contratos de consumo}

La ineficacia del negocio jurídico es la sanción que se establece sobre el acto jurídico, cuando se omiten ciertas condiciones en el momento de su formación, esta sanción consiste en la privación de sus efectos y la terminación del acto. ${ }^{11}$

En materia de contratos de consumo ha sido necesario objetivar ciertas causales de ineficacia ya que la aplicación de los preceptos del derecho común en la materia deviene insuficiente para controlar la validez de estos. En efecto, las características de la contratación en la sociedad del consumo evidenciaron prontamente que el control de la validez del contrato del derecho común no es idóneo para corregir las injusticias contractuales frente a las cuales hoy en día nos vemos enfrentados. El clásico control de validez por vicios del consentimiento se torna insuficiente en esta materia. Cárdenas (2007) sobre este punto sostiene que:

"la realidad demostró que dichos mecanismos eran insuficientes, particularmente cuando apareció la contratación masiva, lo cual dio lugar al surgimiento de la teoría de los contratos de adhesión, que no produjo los resultados que deseaban sus autores. En efecto, la jurisprudencia y la doctrina aplicaron a dichos contratos las reglas generales que se acomodaban particularmente bien a los contratos de adhesión, como aquella de acuerdo con la cual los contratos ambiguos deben interpretarse en contra de quien los redactó. Así mismo, se acudió a los, principios generales de los contratos para determinar qué incluía el contrato y por ello excluir aquellos documentos post-contractuales que en el fondo implican una voluntad de una de las partes de modificar lo previamente acordado. De otra parte, en ciertos contratos el legislador ha intervenido estableciendo diversas normas prohibitivas o restrictivas que en fondo protegen a un contratante. Ahora bien, el progreso económico ha demostrado que esos mecanismos son insuficientes. Es necesario establecer nuevos sistemas para la protección de los contratantes".

Gual (2008) manifiesta que: "en el contrato estándar, el particular solo adhiere al contenido del contrato sin poder modificar las singulares cláusulas, perdiendo aplicabilidad el error, el dolo y la violencia, la defensa del cliente se deja a normas y principios de orden público que prohíban cláusulas que sean por su gravedad, injustas (...) Como manifestación de esta tendencia surgen las leyes de protección de los consumidores y usuarios, de los inquilinos y de los trabajadores, de similar manera son una tendencia de esta manifestación esta tendencia, las leyes que imponen formalismos contractuales, las presunciones de abusividad, así como aquellas que imponen

11 El diccionario enciclopédico de derecho usualmente define la ineficacia como la falta de eficacia, de consecuencia o efectos normales. Lo hecho normalmente pero carente de valor. Ineficacia de los negocios jurídicos: carencia de efectos jurídicos de los mismos (Cabanellas 1997). 
cargas de información, o la obligación de entregar documentos escritos y firmados para que los contenidos del contrato sean válidos".

Al respecto, si tomamos un ejemplo, la inclusión de una cláusula leonina en un contrato celebrado entre un productor y un consumidor puede ser analizada como fuerza o violencia que vicia el consentimiento, la Corte Suprema de Justicia colombiana lo ha dado a entender así. En la misma línea Cárdenas (2010) sostiene que esta fórmula de control es aplicable en Colombia.

También se podría configurar dolo como vicio del consentimiento en el caso de la publicidad engañosa (sin que se puedan predicar dolos buenos, o mentiras validas en el comercio, como lo hacen algunos doctrinantes, a diferencia de la publicidad hipérbole),lo cual resulta de poca aplicabilidad práctica, sobre todo por la dificultad para el consumidor de probar la intención de defraudar. En el derecho civil clásico se hablaba de un dolo bueno y un dolo malo, este dolus bonus o tolerado consistente en ciertas mentiras toleradas (Tamayo, 1994) o engaños admitidos en el comercio y que no son censurables, que además no tiene consagración legal en Colombia. En el derecho del consumo no es aceptado, por tal motivo Lorenzetti (2003) señala que "En cambio, en el derecho del consumidor hay una clara tendencia a considerar ilegítimo el ocultamiento de información, aunque el propósito o sea el engaño (...) La ley obliga a ser "claros y sinceros", lo cual aplica a todo deber de información".

No obstante, a pesar de que a partir del derecho común se puedan predicar algunas soluciones para estos casos por la vía de la nulidad del acto, en el caso del derecho del consumo no se trata de una solución eficaz para el consumidor, puesto que en muchos casos no estará el consumidor en disposición de demandar la ineficacia del contrato o de una cláusula del mismo, por la vía de los vicios del consentimiento a causa de la carga probatoria que tiene a su cargo, a lo que se aúna que la cuantía de los asuntos de consumo en muchos casos son mínimas y el procedimiento a seguir en el ordenamiento jurídico colombiano es el proceso ordinario para este tipo de asuntos. Resulta más viable objetivar la cau- sal a través de la sanción de ciertas conductas contractuales tipificadas, en el derecho comparado se ha optado por acudir a esta vía. Las soluciones para el consumidor para que la protección sea eficaz depende de dos aspectos: la objetivación de las causales de ineficacia y la creación de procedimientos agiles para lograr su declaratoria.

Las normas del derecho común no fueron pensadas para este tipo de relaciones contractuales, y pretender que a través de su aplicación se pueda proteger al consumidor es iluso. Tampoco un ordenamiento jurídico puede depender de la invocación de principios generales del derecho como la buena fe para corregir situaciones contractuales injustas con el consumidor, esto no garantiza nada. Todo esto hace necesario que la normatividad de protección al consumidor prescinda de la teoría clásica para crear soluciones contractuales adecuadas a los desafíos de las relaciones contractuales y precontractuales de consumo. En tal sentido, se crearon controles contractuales para ciertas eventualidades que se pueden presentar en este tipo de contratación, tales como el control de cláusulas abusivas.

\section{El control de cláusulas abusivas}

En el ítem relativo a la interpretación de los contratos de consumo se concluía con la evidencia un vacío normativo, no tanto en lo que se refiere a la interpretación del contrato de consumo, como frente al control de disposiciones contractuales impuestas que se consideran abusivas. En efecto en el derecho comparado encontramos un marco legal amplio referente a lo que se denominan las cláusulas abusivas con el consumidor. Se ha definido una cláusula abusiva como aquella que "redactada por la parte poderosa, crea un desequilibrio significativo en detrimento de la parte débil" (Calais-Auloy, 2006), el Código del Consumo francés las define como "las que tiene como objeto o por efecto crear en detrimento del no profesional o consumidor, un desequilibrio significativo entre los derechos y las obligaciones de las partes del contrato". Para Ghersi (2006) la cláusula abusiva se define como: "aquella que importa un desequilibrio significativo en los derechos y obligaciones reciprocas, desquiciando injustificadamente el sinalagma, lo 
que determina la alteración del principio de equivalencia funcional de las prestaciones". La Ley 1480 de 2011 de protección al consumidor colombiana consagra en el artículo 42 por primera vez una definición legal de la cláusula abusiva: "Son cláusulas abusivas aquellas que producen un desequilibrio injustificado en perjuicio del consumidor y las que, en las mismas condiciones, afecten el tiempo, modo o lugar en que el consumidor puede ejercer sus derechos. Para establecer la naturaleza y magnitud del desequilibrio, serán relevantes todas las condiciones particulares de la transacción particular que se analiza".

Las cláusulas abusivas son frecuentes en los contratos de consumo por las características que ya anotadas que tiene esta modalidad de contratación, al respecto Gual (2009) manifiesta que:

"El uso de semejantes cláusulas suele aparecer de manera preestablecida por el contratante fuerte en los contratos de adhesión a condiciones generales de manera estándar, modalidad de contratación que suele ser utilizada como una manera de contratar constante en el rápido tráfico económico, para la entrega o suministro de bienes. En estos contratos es inquietante el pacto de potenciales cláusulas abusivas que son aceptadas por el contrate débil, situación que parece ser más evidente cuando se está en presencia de una relación contractual con el consumidor, es decir, a un contrato celebrado entre un profesional de una actividad y un consumidor o usuario".

El control de cláusulas abusivas se puede afirmar que es un control parcial de la eficacia del contrato, no afecta la totalidad del mismo sino la eficacia de una o varias de sus cláusulas.

Se evidencia en el derecho comparado una tendencia legislativa sancionar este tipo de cláusulas a través de dos formas, la definición de la cláusula abusiva y la consagración de una prohibición general de incluir esta clase de disposiciones, así como la tipificación a través de listados de cláusulas que se consideran abusivas, por ejemplo el BGB alemán y el Código del Consumo francés. En ambos casos se sanciona la cláusula con la ineficacia. En cuanto a la tendencia de enlistar las cláusulas que se consi- deran abusivas se han generado tres tipos de listas, listas negras, cláusulas que se consideran abusivas sin que se admita prueba en contrario (presunción de derecho), listas grises con cláusulas que se presumen abusivas pero se admite prueba en contrario (presunción de hecho) y el sistema de listas blancas sin presunción (Gual, 2009).

En el contexto normativo colombiano, previo a la reforma al estatuto de protección al consumidor que entrará próximamente en vigencia, varias normas ya se habían referido a cierto tipo de cláusulas prohibidas en los contratos. La Ley 142 de 1994, de servicios públicos domiciliarios, en su artículo 133 establece un control sobre cláusulas abusivas bajo la figura del abuso de posición dominante contractual. Así mismo, la reforma financiera, ley 1328 del 15 de julio de 2009, en su artículo 7 impone a las entidades vigiladas el deber de: "Abstenerse de incurrir en conductas que conlleven abusos contractuales o de convenir cláusulas que puedan afectar el equilibrio del contrato o dar lugar a un abuso de posición dominante contractual", así como en el capítulo $\mathrm{V}$ se refiere a las cláusulas y prácticas abusivas, elaborando un listado de unas y otras. Esta norma además contempla que: "cualquier estipulación o utilización de cláusulas abusivas en un contrato se entenderá por no escrita o sin efectos para el consumidor financiero", dando a entender que la sanción a la cláusula es la ineficacia de pleno derecho a que se refiere el artículo 897 del Código de Comercio. A través de las resoluciones 037 y 038 de septiembre de 2011 la Superintendencia Financiera amplió el listado de cláusulas en los contratos financieros.

Encontramos igualmente en materia de telecomunicaciones la Resolución 1732 de 2007 de la Comisión de Regulación de Telecomunicaciones que atinente al régimen de protección de los suscriptores y/o usuarios de los servicios de telecomunicaciones que en su artículo 12 prohíbe en los contratos de prestación de estos servicios cláusulas que excluyan y limiten las responsabilidad del prestador del servicio, que den a los operadores la facultad de terminar unilateralmente el contrato por causales distintas al incumplimiento del contrato, fuerza mayor o casuales legales, las que impongan al suscriptor una renuncia anticipada a cualquiera de los derecho que el contrato o la ley le 
conceden, entre otras. La Resolución 3066 de 2011 de la Comisión de Regulación de Comunicaciones (CRC) en su artículo 14 incluye un listado de cláusulas prohibidas en los contratos de prestación de servicios de telecomunicaciones. Estas normas hasta hoy regulaban de una dispersa el control de cláusulas abusivas, sin que en ellas se definiera esta figura. Con la ley 1480 de 2011 surge una definición legal y de paso se incluye un nuevo listado de cláusulas.

Tampoco se evidenciaba claramente cuál sería la sanción al negocio jurídico en materia de cláusulas abusivas, es decir, qué tipo de ineficacia se predicaría en presencia de una cláusula de estas, dado que en materia financiera se sancionan con ineficacia de pleno derecho y en comunicaciones según la resolución 3066 de 2011 dice que "no surtirán efectos jurídicos y se tendrán por no escritas", lo que nos lleva al mismo tipo de sanción, sin embargo se trata de regímenes especiales. La nueva ley de protección al consumidor las sanciona con ineficacia de pleno derecho y de paso al ser un régimen general en materia de derecho del consumo deja resuelto el inconveniente.

Sin embargo, de la lectura de estas normas y de la doctrina surge un interrogante, ¿̇el abuso de posición dominante contractual y el control sobre cláusulas abusivas se refieren a un mismo fenómeno jurídico?

\section{El abuso de posición dominante contractual}

La doctrina nacional con base en antecedentes jurisprudenciales viene hablando del "abuso de la posición dominante contractual", la premisa de la que se parte es que existen contratos en que uno de los contratantes tiene posición de dominio frente a su co-contratante. Arrubla (2007) la define así: "la posición dominante de una empresa en la contratación se presenta cuando formula previa y unilateralmente el contenido del contrato con el cual se presentara ante sus consumidores". Esta posición de dominio contractual aunque no es exclusiva de los contratos de consumo, tendrá ocurrencia frecuente en este tipo de contratos debido a la asimetría contractual que se presenta estos. Márquez (2007) afirma al respecto que "Si el mercado no es de competencia perfecta, y especialmente cuando tal causa está dada por la asimetría de la información debido a la información incompleta, se genera una posición de dominio de la que es fácil abusar por parte del conocedor de la información". Pero esta posición de dominio no se circunscribe al tema de la información, el poder económico, el saber especializado del productor y el poder de negociación, de una parte frente a la otra en el contrato, también generan este desequilibrio. En cuanto al poder de negociación, la Corte Suprema de Justicia colombiana ha sostenido que la entidad bancaria tiene posición dominante frente al usuario, en sentencia de 1994 al respecto afirmo:

"Y un ejemplo sin duda persuasivo de esa clase de comportamientos irregulares lo suministra el ejercicio del llamado "poder de negociación" por parte de quien, encontrándose de hecho o por derecho en una posición dominante en el tráfico de capitales, bienes y servicios, no solamente ha señalado desde un principio las condiciones en que se celebra determinado contrato, sino que en la fase de ejecución o cumplimiento de este último le compete el control de dichas condiciones, configurándose en este ámbito un supuesto claro de abuso cuando, atendidas las circunstancias particulares que rodean el caso, una posición de dominio de tal naturaleza resulta siendo aprovechada, por acción o por omisión, con detrimento del equilibrio económico de la contratación (...) Dicho en otras palabras, la banca en sus diferentes manifestaciones es una compleja amalgama de servicio y crédito donde las empresas financieras que la practican disponen de un enorme poderío económico que, "(...) barrenando los principios liberales de la contratación (...)" como lo dijera un renombrado tratadista (Joaquín Garrígues. Contratos Bancarios, cap. 1., num, II), les permite a todas las de su especie gozar de una posición dominante en virtud de la cual pueden predeterminar unilateralmente e imponerla a los usuarios, las condiciones de las operaciones activas, pasivas y neutras que están autorizadas para realizar, así como también administrar el conjunto del esquema contractual de esa manera puesto en marcha, pero no obstante ello, preciso es no perder de vista que en el ejercicio de estas prerrogativas de suyo reveladoras de una significativa desigualdad en la negociación, los intereses de los clientes no pueden menospreciarse. Si así llega a ocurrir porque la 
entidad crediticia, con daño para su cliente y apartándose de la confianza depositada en ella por este último en el sentido de que velará por dichos intereses con razonable diligencia, se extralimita por actos $\mathrm{u}$ omisiones en el ejercicio de aquellas prerrogativas, incurre en el abuso de la posición preeminente que posee (...)". En breve síntesis equivale a decir que para el legislador la posición dominante de las entidades de crédito es un dato de hecho acerca de cuya realidad no hay controversia judicial posible $y$, así mismo, que en cuanto esa posición es determinante para quien goza de situaciones particulares o activas de poder, en su desarrollo práctico dentro del contorno que marcan las relaciones contractuales por dichas entidades establecidas con sus clientes, hay lugar al abuso en perjuicio de estos últimos."

Uno de los riesgos de la contratación de consumo, al tener las características señaladas, radica en la posibilidad de que la parte fuerte del contrato, el productor, quien tiene el poder económico que le permite controlar el contenido contractual, abuse de esta posición dominante y desequilibre excesivamente el contrato en detrimento de la parte débil, el consumidor. La Constitución política colombiana sanciona el abuso de posición dominante concurrencial, aquel que se da en el mercado, pero no se refiere al abuso de posición dominante contractual, aunque Cárdenas (2007) y Arrubla (2007) justifican la protección del contratante débil desde el ámbito constitucional basado en el artículo 13 de la Constitución Política de Colombia que señala: "El estado protegerá especialmente a aquellas personas que por su condición económica, física o mental, se encuentren en circunstancia de debilidad manifiesta y sancionara los abusos o maltratos que contra ellas se comentan", esta posición es acertada, ya que se encuentra plenamente demostrado que el consumidor es una persona que se encuentra en estado de debilidad económica en las relaciones jurídicas- patrimoniales con el productor, por lo tanto incluir al consumidor como sujeto de tutela jurídica con base en esta norma tiene un alto grado de lógica. Sin embargo la invocación y aplicación práctica de esta norma cons- titucional para corregir desequilibrios contractuales se torna de difícil aplicación por parte de los jueces, por lo que se hace necesario legislar expresamente para lograr el control de estas situaciones contractuales (Arrubla, 2007).

Algunas de las prácticas contractuales en que incurren los prestadores de servicios son abusivas, ya sea porque incluyan cláusulas abusivas en el contrato a condiciones generales que imponen a sus usuarios, ora porque no estando estipulado en el contrato aplican condiciones arbitrarias a sus usuarios (ej. aceptación de servicios no solicitados, cobros no pactados, aplicación de sanciones no pactadas, entre otros). Por lo tanto la noción de abuso de posición dominante contractual puede extenderse más allá de la mera noción de cláusula abusiva, siendo esta tan solo una forma en las que se manifiesta el abuso de posición dominante contractual. La reforma financiera de 2009 de manera acertada hace la diferencia entre prácticas abusivas y cláusulas abusivas cobijando varias formas de abuso de posición dominante contractual.

En el derecho europeo se sancionan además las prácticas desleales de comercio, vistas desde el punto de vista del consumidor y no de la competencia. El Código del Consumo francés por ejemplo, en el artículo L120-1 define las prácticas comerciales desleales así: "Una práctica comercial es desleal cuando es contraria a las exigencias de la diligencia profesional y altera, o es susceptible de alterar de manera sustancial, el comportamiento económico del consumidor normalmente informado y razonablemente atento, con respecto a un bien o servicio". Igualmente este código dice que constituyen prácticas comerciales desleales las prácticas comerciales engañosas y las prácticas comerciales agresivas. La Directiva comunitaria europea 2005/29 referente a las prácticas de comercio desleales habla de influencia indebida ${ }^{12}$ y lo que llama la atención es que se refiere a la utilización de una posición de poder del productor frente al consumidor que limita la capacidad de decisión del consumidor. Este tipo de prácticas se dividen en

12 Influencia indebida: utilización de una posición de poder en relación con el consumidor para ejercer presión, incluso sin usar fuerza física ni amenazar con su uso, de una forma que limite de manera significativa la capacidad del consumidor de tomar una decisión con el debido conocimiento de causa. 
prácticas comerciales engañosas y prácticas comerciales abusivas. De acuerdo a esas definiciones una práctica comercial desleal es otro tipo de conducta ilícita que atenta contra los derechos de los consumidores, que implica un abuso del poder del productor frente al consumidor y que generalmente es precontractual. Aunque se trata evidentemente de una categoría autónoma se quiere resaltar que en el derecho comunitario europeo se le considera una forma de abuso de poder.

La Ley 1480 de 2011 regula en Colombia dos tipos de prácticas que pueden ser consideradas abusiva, en el caso de envío de productos no requeridos y las ventas atadas (artículo 34 y 35), eventos que corresponden a lo que se conoce como prácticas de comercio agresivas o desleales. En el caso de los productos no requeridos es común en el mercado colombiano la práctica mediante la cual el prestador del servicio somete el rechazo de una nueva prestación a la manifestación expresa del consumidor, de tal forma que si no comunica su negativa se entenderá que se obligó, presumiéndose la aceptación del consumidor. A manera de ejemplo, el envío de tarjetas de crédito no solicitadas, revistas de farándula no solicitadas, mensajes de texto que ofrecen nuevos servicios y le imponen al consumidor enviar un mensaje para rechazar el servicio. En el caso de las ventas atadas es conocido el caso de los bancos que obligaban al solicitante de un préstamo a adquirir un seguro de vida con la aseguradora del mismo grupo empresarial.

En el ámbito del derecho del consumo colombiano el abuso de posición dominante contractual presenta además una dificultad de tipo práctico, el control sobre este tipo de situaciones es de competencia de la justicia ordinaria, la Superintendencia de Industria y Comercio (SIC) ha reiterado que si el abuso de posición dominante que se denuncia no es concurrencial esta entidad no tiene competencia para pronunciarse $e^{13}$ y mucho menos cuenta con funciones jurisdiccionales al respecto, lo cual deja un vacío en el propósito de tutelar al consumidor porque la cuan- tía de un problema suscitado entre un prestador de un servicio y un usuario no ameritara en la mayoría de los casos el inicio de un procedimiento ante la justicia ordinaria, por los costos y el tiempo que tomaría un pleito de esta naturaleza para el consumidor, quedándose en consecuencia sin sanción este tipo de conductas y el consumidor o usuario a merced de los abusos de que eventualmente pueda ser víctima. Evidentemente estos casos no tenían protección legal efectiva en el ordenamiento jurídico colombiano, aunque en otros aspectos como en materia de aplicación de garantías el asunto es netamente contractual y la SIC legalmente tiene y viene ejerciendo funciones jurisdiccionales.

En realidad sería deseable que se contemplaran soluciones eficaces para tutelar al consumidor en estos casos, los jueces civiles a podrían hacerlo a través de procedimientos sumarios (no ordinarios) o la misma SIC, con la ventaja de ser un juez especializado, debería tener funciones jurisdiccionales para resolver estos asuntos. La ley 1480 de 2011 presenta una solución al problema ya que a través de la acción de protección al consumidor se podrán tramitar asuntos relacionados con la vulneración de los derechos del consumidor y la protección contractual al consumidor, lo cual implica que desde ahora la SIC tendrá funciones de juez en asuntos contractuales de consumo regulados por las normas de protección al consumidor de manera general (al igual que la Superintendencia Financiera en casos de su competencia). El problema radica en que la misma norma hace énfasis en que se trate de asuntos relacionados con la infracción de normas de protección al consumidor y al no haber una norma que de manera general sancione las prácticas abusivas de comercio, quedarían por fuera de la competencia de la SIC algunos casos no reglamentados por la norma.

En síntesis, esta noción de abuso de posición dominante contractual de la que se habla en el ámbito colombiano presenta aún deficiencias en su concepción teórica y en los mecanismos tendientes a su protección legal en materia de protección al consumidor.

13 Resolución 3444 de 2008. Superintendencia de Industria y Comercio. 


\section{El derecho de retracto}

El derecho de retracto, contemplado en algunos ordenamientos jurídicos, es una prerrogativa que se le da al consumidor en ciertos contratos de consumo de terminar el contrato, de arrepentirse, de desistir en la celebración del mismo con posterioridad a la celebración del mismo, durante un término establecido por la ley. Esta figura que es bastante simple implica una derogación de los postulados del derecho civil clásico.

En cuanto a la naturaleza jurídica del derecho de retracto se trata de una figura que rompe el esquema de la contratación tradicional que sanciona la terminación unilateral de un contrato como regla general, y además constituye una excepción al principio pacta suntservanda, el contrato se encuentra celebrado y en ejecución o ya ejecutado, sin embargo el consumidor tiene la prerrogativa de resolverlo sin una causa justificada. No se trata pues de una especie de ineficacia, el contrato es plenamente valido, se podría concebir como una condición resolutoria meramente potestativa que depende de la voluntad del consumidor.

El derecho de retracto es muy común en el caso de las ventas a distancia (Ej. televentas, ventas por catálogo, contratos celebrados por internet o por medios electrónicos), en las ventas a domicilio o las realizadas fuera del establecimiento comercial del vendedor.

En la legislación argentina el derecho de retracto está contemplado en el artículo 34 de la Ley 24.240 aplicable a la venta por correspondencia y a la venta domiciliaria concede un plazo de diez días a partir de la recepción del bien al consumidor para revocar la aceptación del contrato. En la legislación francesa el artículo L 121-20 del Código del Consumo, en materia de ventas de bienes o prestación de servicios a distancia, le concede un plazo de siete días al consumidor para ejercer el derecho de retracto sin necesidad de justificar el motivo ni de pagar penalidades, contados a partir de la recepción del bien en caso de ventas o de la aceptación de la oferta en caso de prestación de servicios. En materia de servicios financieros este plazo para ejercer el derecho de retracto se amplía a 14 días en algunos casos. En materia de ventas a domicilio el mismo código francés contempla un término de reflexión de siete días para que el consumidor pueda rescindir el contrato sin penalidad alguna. Aclara Calais-Auloy (2006) que el derecho de retracto que se aplica en materia de ventas a distancia y el derecho de reflexión que se aplica en materia de ventas a domicilio tienen una naturaleza diferente, el derecho de retracto se justifica, porque en las ventas a distancia el comprador ordena sobre la fe que le dan ciertas imágenes o descripciones, de tal manera que corre el riesgo de recibir algo que no corresponda a lo que había ordenado.

Mientras que el consumidor que se encuentra frente al vendedor domiciliario tiene un riesgo diferente que consiste en no poder reflexionar lo suficiente sobre la conveniencia de la compra (Calais-Auloy, 2006). En la legislación española aparece el derecho de retracto en el artículo 44 de la Ley 47 de 2002, que concede un plazo de siete días al consumidor para desistir del contrato sin penalización alguna y sin indicar los motivos. Note que la normatividad española y la francesa (así como otras regulaciones nacionales de estados miembros de la UE) están armonizadas como quiera que las dos legislaciones fueron modificadas para dar lugar a la transposición de la directiva 97 / 7 CE sobre ventas a distancia, con la diferencia que la normatividad francesa fue un poco más amplia.

En el ordenamiento jurídico colombiano el Decreto 3466 de 1982 en su artículo 41 consagra la posibilidad de retracto para cualquiera de las partes en contratos de ventas de bienes o servicios celebrados por sistemas de financiación, dentro del término de dos días. Esta norma se focaliza en la modalidad de pago para establecer la prerrogativa de retracto y lo hace de una manera diferente a las normas ya citadas pues contempla esta posibilidad para ambas partes. Ahora la Ley 1480 de 2011 consagra un nuevo derecho de retracto aplicable en tres casos, para ventas de bienes y prestación de servicios mediante sistema de financiación otorgada por el productor o proveedor, en el caso de venta de tiempos compartidos, y en el caso de ventas realizadas a través de métodos no tradicionales o a distancia. En esos ca- 
sos se entenderá pactado el derecho de retracto a favor del consumidor quien podrá resolver el contrato dentro de los cinco (5) días siguientes a la entrega del bien o celebración del contrato de prestación de servicios. La misma norma consagra algunos eventos en que no se aplicará este derecho, como en el caso en que se haya comenzado a ejecutar el contrato de prestación de servicios, en caso de suministro de bienes confeccionados personalizados conforme a las especificaciones del consumidor, en la adquisición de bienes perecederos, de bienes de usos personal, de juegos y loterías, entre otros. Esta nueva norma implica un avance significativo ya amplía el margen de cobertura del retracto, que se encontraba supremamente limitado en el Decreto 3466 de 1982, no solamente en el tiempo que se tiene para hacer uso de este, que pasa de dos (2) a cinco (5) días, sino que cobija las ventas a distancia o por métodos no tradicionales, lo cual se refiere a televentas, ventas por teléfono, ventas por catálogo, ventas por internet y ventas realizadas fuera del local comercial del producto y/ proveedor, entre otras. Igualmente, cobijará el contrato de tiempo compartido que ha generado tantos problemas en otros países y en menor medida en Colombia (ver anexo 2).

\section{Conclusiones}

Considerar el contrato de consumo como una categoría contractual es válido, se evidencian dos clases de estos, los contratos objetivos de consumo y los contratos subjetivos de consumo. Los contratos objetivos de consumo son aquellos en que independientemente de la existencia de una relación de consumo productor- consumidor se aplica el régimen de protección al consumidor. Los contratos subjetivos de consumo son aquellos en que necesariamente se debe establecer la existencia de una relación de consumo para aplicar la normatividad de protección al consumidor.

Las nociones de relación de consumo y contrato de consumo están estrechamente vinculadas y son dos figuras jurídicas independientes que no se excluyen.

El contrato de consumo adquiere fisonomía propia por sus características, es generalmente contrato de adhesión, se evidencia la presencia de un contratante en posición de debilidad, tiene un margen de protección legal más amplio para la parte débil, el consentimiento es informado, tiene unas normas de interpretación especiales.

Los remedios clásicos frente a la ineficacia de los contratos no operan de manera efectiva en materia de contratos de consumo, en estos casos es necesario ampliar el margen de protección y buscar causales de ineficacia acordes con las características de los contratos de consumo. En aras de proteger al contratante débil (consumidor) debe tratarse de causales objetivas de ineficacia.

La eficacia del contrato de consumo se puede ver afectada por la inclusión de cláusulas abusivas por parte del productor o por la ocurrencia de prácticas de comercio desleales o abusivas con el consumidor. El control a este tipo de conductas debe ser de tipo administrativo en contra del productor (a través de multas) y de tipo contractual con el fin de procurar el reequilibrio contractual quebrantado por la conducta.

El sistema de control de cláusulas abusivas con el consumidor en el derecho comparado se encuentra desarrollado ampliamente. En Colombia este control es nuevo, con la nueva ley de protección al consumidor (Ley 1480 de 2011) surge un régimen general en materia de derecho del consumo. En materia de servicios financieros, comunicaciones y servicios públicos domiciliarios se encuentra legislado parcialmente el tema. La sanción jurídica a este tipo de cláusulas en el régimen colombiano es ineficacia del pleno de derecho.

En materia de protección al consumidor el abuso de posición dominante contractual es de frecuente ocurrencia dada la asimetría de las parte en la relación contractual ya sea desde el punto de vista de la información como del poder económico y de negociación.

La figura del abuso de posición dominante contractual, es reducida por la doctrina colombiana al régimen de control de cláusulas abusivas, siendo una figura más amplia que cobija también la ocurrencia de las denominadas prácticas abusivas. Las prácti- 
cas de comercio desleales constituyen una categoría diferente que ha sido desarrollada en el derecho comunitario europeo y que se funda en lo que se considera un abuso de poder del productor frente al consumidor.

Ahora en nuestro país el control de la ineficacia de los contratos de consumo está sometido al régimen del derecho común, con excepción de las normas especiales citadas, y además es de conocimiento de los jueces ordinarios a través de los procedimientos comunes. Esto afecta la efectividad de la protección de los derechos de los consumidores, ya que dadas las cuantías de los asuntos del derecho del consumo no es viable acudir a procedimientos largos ante la justicia amparados en causales subjetivas de ineficacia. Con la nueva ley de protección al consumidor el régimen protección contractual se amplía, la Superintendencia de Industria y Comercio aumenta sus funciones jurisdiccionales y se ocupará de resolver asuntos contractuales de consumo.

El derecho de retracto en una figura sui generis que busca proteger la manifestación de voluntad del consumidor sobre todo en contratos celebrados a distancia o fuera del establecimiento de comercio. Se trata de una figura jurídica muy sencilla en su concepción pero que en su comprensión rompe con los postulados clásicos de la contratación. En Colombia tiene hasta ahora una aplicación reducida, a diferencia de los casos en que se aplica en el derecho comparado. La nueva ley de protección al consumidor amplía el alcance de este derecho.

\section{Referencias}

Arrubla, J. (2007). Abuso de la posición dominante contractual, en Regulación financiera y bursátil y derechos del consumidor. Biblioteca jurídica Dike, Medellín.

Arrubla, J. (2008) Contratos mercantiles, tomo III, ediciones jurídicas Dike, Bogotá

Auguet, Y. (2008) Droit de la consommation, Ellipses, Paris.

Cabanellas, G. (1997). Diccionario enciclopédico de derecho usual. Tomo IV. Editorial Heliasta, Buenos Aires.

Calais-Auloy, J. (2006) Droit de la consommation, Dalloz, Paris.

Cárdenas, J. (2010). Contratos comerciales presente y futuro. En : Memorias II Congreso Internacional de Derecho Comercial, Cámara de Comercio de Bogotá.
Cárdenas, J. (2007). Justicia y abuso contractual. Los contratos en el derecho privado. Editorial Legis, Bogotá.

Díez Picazo, L. \& Gullón, A. (2001). Sistema de Derecho Civil. Vol. II. Ed. Tecnos, Madrid.

Ghersi, C. (2005). Contratos de consumo. Editorial Astrea, Buenos Aires.

Ghersi, C. (2006). Contratos civiles y comerciales. Editorial Astrea, Buenos Aires.

Gual, J. (2009). El control de cláusulas abusivas, un régimen en evolución. En: Revista IUSTA, No.30.

Löfgren, K-G, Persson, T. \& Weibull, J. (2002). Markets with Asymmetric Information: The Contributions of George Akerlof, Michael, Spence and Joseph Stiglitz, En: The Scandinavian Journal of Economics, 104 (2): 197-198

Lorenzetti, R. (s.f). Tratado de los contratos. Rubinzal Culzoni Editores, Buenos Aires.

Lorenzetti, R. (2003). Consumidores. Rubinzal Culzoni Editores, Buenos Aires.

Márquez, R. (2007) Apuntes de derecho económico y de la competencia, Pontificia Universidad Javeriana, Bogotá

Monsalve, C. (2010) la responsabilidad precontractual, Grupo editorial Ibañez, Bogotá.

Pérez, A. (2009). Teoría general de las obligaciones. Obra revisaday actualizada por Alberto Tamayo Lombana. Vol. I. Parte primera. De las fuentes de las obligaciones. Bogotá, Doctrina y ley.

Piris, C. (2004) Los conceptos fundamentales del derecho del consumidor en el Mercosur. En: Internationa Law. Revista Pontificia Universidad Javeriana, Bogotá.

Poillot, E. (2006) Droit Européen de la Consommation et uniformisation du droit des contrats, $1^{\text {er }}$ édition. Ed. LGDJ, Paris.

Rinessi, A. (2006) Relación de consumo y derechos del consumidor. Editorial Astrea, Buenos Aires.

Rusconi, D. (2009). Esencia del derecho del consumidor. En: Rusconi, D. (coord) Manual de Derecho del consumidor. Abeledo Perrot, Buenos Aires.

Solarte, A. (2008). La buena Fe contractual y los deberes secundarios de conducta, en Contratos, derecho Privado y Globalización. Tomo III. Editorial Ibañez, Bogotá.

Stiglitz, J. (1999) Knowledge for Development: Economic Science, Economic Policy, and Economic Advice. Proceedings from the Annual Bank Conference on Development Economics 1998. World Bank, Washington D.C.

Stiglitz, J. \& Rothschild, M. (1976). Equilibrium in Competitive Insurance Markets: An Essay on the Economics of Imperfect Information". En: The Quartely Journal of Economics, 90 (4): 629 - 649.

Superintendencia de industria y comercio (s.f). Guía del consumidor. Recuperado el 30/09/2010. Disponible en: http://www.sic.gov. co/archivo_descarga.php?idcategoria $=1520$

Tamayo, A. (199̄4). Manual de obligaciones: teoría del acto jurídico y otras fuentes. Editorial Temis.

Vallespinos, C. (1984). El contrato por adhesión a condiciones generales. Buenos Aires: Editorial Universidad.

Vega, Y. (2001). Contratos de consumo. Editorial Grijley, Lima.

Velilla, M. (2001). Introducción al derecho de los Negocios. E navegante editores, Medellín.

Villalba, J. (2009). La noción de consumidor en el derecho comparado y en el derecho colombiano. En: Revista Vniversitas, Pontificia Universidad Javeriana, 119: 305-339. 


\section{Anexo $1^{14}$ \\ Jurisprudencia revisada en el artículo}

Código Civil Colombiano. Disponible en: http://www.encolombia.com/derecho/C\%C3\%B3digoCivilColombiano/CodCivilColombContenido.htm

Código de consumo francés. Disponible en: http://www.legifrance.gouv.fr/affichCode.do;jsessionid=18E2DE99385A705EA84D3 85E99AD684B.tpdjo10v

Constitución de la Nación Argentina (1994). Disponible en: http://www.senado.gov.ar/web/interes/constitucion/cuerpo1.php

Constitución Política de Colombia (1991). Disponible en: http://www.banrep.gov.co/regimen/resoluciones/cp91.pdf

Concepto 01085864 del 22 de Noviembre de 2001. Superintendencia de Industria y Comercio (Colombia).

Concepto 03025237 del 09 de Mayo de 2003. Superintendencia de Industria y Comercio (Colombia).

Concepto 02108233 del 17 de Enero de 2003. Superintendencia de Industria y Comercio (Colombia).

Decreto 410 de 1971. Código de Comercio de Colombia. Disponible en: http://www.secretariasenado.gov.co/senado/basedoc/ codigo/codigo_comercio.html

Decreto 3466 de 1982. Estatuto del Consumidor (Colombia). Disponible en: http://www.ccconsumidores.org.co/index.php?option=com_ content\&view = article\&id=51:decreto-3466-1982-estatuto-del-consumidor\&catid=19:legislacion\&ltemid=126

Decreto 677 de 1995. Régimen de Registros y Licencias, el Control de Calidad, así como el Régimen de Vigilancias Sanitarias de Medicamentos, Cosméticos, Preparaciones Farmacéuticas a base de Recursos Naturales, Productos de Aseo, Higiene y Limpieza y otros productos de uso doméstico. Diario Oficial No. 41.827, del 28 de abril de 1995.

Directiva comunitaria europea 2005/29. Relativa a las prácticas comerciales desleales de las empresas en sus relaciones con los consumidores en el mercado interior. Disponible en: http://eur-lex.europa.eu/LexUriServ/LexUriServ.do?uri=OJ:L:2005:149:0 022:0039:ES:PDF

Directiva 97/7 CE. Protección de los consumidores en materia de contratos a distancia. Disponible en: http://eur-lex.europa.eu/ LexUriServ/LexUriServ.do?uri=CELEX:31997L0007:es:HTML

Lei 8078 de 1990. Código de defesa do Consumidor (Brasil) Disponible en: http://www.planalto.gov.br/ccivil 03/leis/L8078.htm

Ley 42 de 2002. Ordenación del Comercio Minorista (España). Disponible en: http://civil.udg.edu/normacivil/estatal//contract/L47-02.htm

Ley 142 de 1994. Por la cual se establece el régimen de los servicios públicos domiciliarios y se dictan otras disposiciones. Congreso de Colombia. Disponible en: http://www.dmsjuridica.com/CODIGOS/LEGISLACION/LEYES/L0142_94.htm

Ley 1328 de 2009. Protección al Consumidor Financiero. Congreso de Colombia. Disponible en: http://www.superfinanciera.gov. co/ConsumidorFinanciero/ley1328.pdf

Ley 1480 de 2011. Por medio de la cual se expide el Estatuto del Consumidor y se dictan otras disposiciones. Congreso de Colombia. Disponible en: http://www.bibliotecajuridica.com.co/LEY_1480_DE_2011.htm

Ley 24.240 de 1993. Defensa del Consumidor (Argentina). Disponible en: http://www.filo.uba.ar/contenidos/carreras/edicion/catedras/derechos/sitio/leydedefensadelconsumidor.html

Ley 26.361 de 2008. Ley que reforma la Ley 24240 de Defensa del Consumidor (Argentina). Disponible en: http://www.oceba.gba. gov.ar/Descarga/LEY24240.pdf

Ley 29571 de 2010. Códiḡo de protección y defensa del consumidor (Perú). Disponible en: http://portal.andina.com.pe/EDPEspeciales/especiales/2010/setiembre/codigo_consumidor.pdf

Resolución No 123/96. Defensa del Consumidor. MERCOSUR.

Resolución Nº 037 y 038 de septiembre de 2011. Superintendencia Financiera (Colombia).

Resolución No 1732 de 2007. Comisión de Regulación de Telecomunicaciones. Disponible en: http://www.cntv.org.co/cntv_bop/ basedoc/resolucion/crt/resolucion crt 1732 2007.html

Resolución No 3066 de 2011 de la Comisión de Regulación de Comunicaciones (CRC). Disponible en: http://www.crcom.gov. $\mathrm{co} /$ ?idcategoria $=42090$

Resolución No 3444 de 2008. Superintendencia de Industria y Comercio.

Sentencia C-1141 de 2000. Corte Constitucional (Colombia).

Sentencia de 19 de octubre de 1994. Corte Suprema de Justicia, sala de casación civil. Magistrado Ponente Carlos Esteban Jaramillo. Disponible en: Schloss.http://contratosmercantilesosmarose.files.wordpress.com/2011/05/clc3a1usulas-abusivas.pdf

14 Fuente: Elaboración propia. 


\section{Anexo $2^{15}$}

Ley 1480 de 2011

(...) Artículo 47. Retracto. En todos los contratos para la venta de bienes y prestación de servicios mediante sistemas de financiación otorgada por el productor o proveedor, venta de tiempos compartidos o ventas que utilizan métodos no tradicionales o a distancia, que por su naturaleza no deban consumirse o no hayan comenzado a ejecutarse antes de cinco (5) días, se entenderá pactado el derecho de retracto por parte del consumidor. En el evento en que se haga uso de la facultad de retracto, se resolverá el contrato y se deberá reintegrar el dinero que el consumidor hubiese pagado.

El consumidor deberá devolver el producto al productor o proveedor por los mismos medios y en las mismas condiciones en que lo recibió. Los costos de transporte y los demás que conlleve la devolución del bien serán cubiertos por el consumidor.

El término máximo para ejercer el derecho de retracto será de cinco (5) días hábiles contados a partir de la entrega del bien o de la celebración del contrato en caso de la prestación de servicios.

Se exceptúan del derecho de retracto, los siguientes casos:

1. En los contratos de prestación de servicios cuya prestación haya comenzado con el acuerdo del consumidor;

2. En los contratos de suministro de bienes o servicios cuyo precio esté sujeto a fluctuaciones de coeficientes del mercado financiero que el productor no pueda controlar;

3. En los contratos de suministro de bienes confeccionados conforme a las especificaciones del consumidor o claramente personalizados;

4. En los contratos de suministro de bienes que, por su naturaleza, no puedan ser devueltos o puedan deteriorarse o caducar con rapidez;

5. En los contratos de servicios de apuestas y loterías;

6. En los contratos de adquisición de bienes perecederos;

7. En los contratos de adquisición de bienes de uso personal.

El proveedor deberá devolverle en dinero al consumidor todas las sumas pagadas sin que proceda a hacer descuentos o retenciones por concepto alguno. En todo caso la devolución del dinero al consumidor no podrá exceder de treinta (30) días calendario desde el momento en que ejerció el derecho (...).

15 Ley 1480 de 2011. Destacado por el autor. 
